\title{
Electrokinetic Stabilization of Marine Clayey Soils by Different Injection Procedures
}

\author{
Yongqiang Tang ${ }^{1, *}$, Ningwei Wang ${ }^{1,2}$, Tie Liu $^{2}$ \\ ${ }^{1}$ Institute of Engineering Mechanics, China Earthquake Administration; Key Laboratory of \\ Earthquake Engineering and Engineering Vibration of China Earthquake Administration, Harbin \\ 150080, China. \\ ${ }^{2}$ School of Civil Engineering, Shenyang Jianzhu University, Shenyang 110168. \\ *E-mail: tangyongqiang200@sina.com
}

doi: $10.20964 / 2021.02 .24$

Received: 12 August 2020 / Accepted: 3 November 2020 / Published: 31 December 2020

The nonuniform improvement of strength in marine clayey soils is one of a primary problem observed when electroosmosis treatment is conducted in these soils. Five group tests were conducted to access the effect of electrokinetic stabilization on treatment of soft clay by different injection procedure of $\mathrm{Ca}^{2+}$ and $\mathrm{SiO}_{3}{ }^{2-}$ ions. The current, drainage rate, energy consumption and bearing capacity were analyzed. The results show that the injection of $\mathrm{CaCl}_{2}$ and $\mathrm{Na}_{2} \mathrm{SiO}_{3}$ at the anode and cathode, respectively, is the most effective operation procedure. Consequently, most of the soil surface bearing capacity is higher than $180 \mathrm{kpa}$, accounting for $70.4 \%$ of the total soil sample area, the increase in strength was attributed to injection of up to $43 \%$ of chemical additives after a 14-day curing were measured in the middle zone.

Keywords: Electrokinetic Stabilization; Soil improvement; Injection procedure; Chemical solution.

\section{$\underline{\text { FULL TEXT }}$}

(C) 2021 The Authors. Published by ESG (www.electrochemsci.org). This article is an open access article distributed under the terms and conditions of the Creative Commons Attribution license (http://creativecommons.org/licenses/by/4.0/). 